\title{
Efficiency improvement of dual three-phase permanent magnet synchronous motor using modified switching table DTC for electric ship propulsion
}

\author{
Aziz El Afia ${ }^{1}$, Mhammed Hasoun ${ }^{2}$, Mohamed Khafallah ${ }^{3}$, Karim Benkirane ${ }^{4}$ \\ ${ }^{1}$ Departement of Electrical Engineering, Hassan II University, National High School of Arts and Crafts "ENSAM", \\ Morocco \\ ${ }^{2,3,4}$ Departement of Electrical Engineering, Hassan II University, National High School of Electricity and Mechanics \\ "ENSEM", Morocco
}

\begin{abstract}
Article Info
Article history:

Received Sept 16, 2020

Revised May 2, 2021

Accepted July 12, 2021

Keywords:

DTP-PMSM

Electric ship propulsion

Harmonic currents

ABSTRACT

A direct torque control using a classical switching- table ST-DTC can be used to control the torque and thus the speed of Dual Three-Phase Permanent Magnet Synchronous Motor (DTP-PMSM). The principle is based on direct application of control sequence by using two hysteresis regulators and a switching table. A large stator current containing low order harmonics is produced during the application of the classic ST-DTC technique, this leads to higher losses affecting the efficiency of the machine. To allow a reduction of these harmonics a modified switching-table approach based DTC technique is examined. Indeed, an improved ST-DTC strategy, which consist of replacing the vectors of the classical table with synthetic vectors, is discussed. The simulation results confirm the validity of the selected strategy.
\end{abstract}

Switching table-DTC

Vector space decomposition

This is an open access article under the CC BY-SA license.

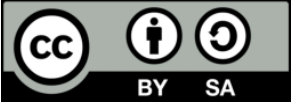

\section{Corresponding Author:}

Aziz El Afia

Departement of Electrical Engineering

Hassan II University

National High School of Arts and Crafts "ENSAM", Casablanca, Morocco

Email: aziz.elafia@univh2c.ma

\section{INTRODUCTION}

Recently, the all-electric ship concept has become particularly important. Full electric propulsion systems for commercial and military shipping sector have been intensively developed. Electric propulsion offers potential advantages regarding flexibility in ship maneuvering, maintenance cost and vibration level [1], [2]. In the naval industry, three-phase electric machines are mainly the most used. Recently, the use of multiphase machines has grown considerably in several areas including naval propulsion, railway electric traction, electric vehicles, avionics, and high-power industrial applications [3]-[9]. Multiphase machines provide several important benefits in terms of torque quality and machine reliability [1]. The most interesting multiphase machines which attract a lot of interest is the dual three phase (DTP) ones. DTP machines has two sets of three-phase stator windings spatially shifted by 30 electrical degrees with two isolated neutrals [1].

Among all DTP machines the permanent magnet synchronous motor (DTP-PMSM) is the most used one [10]. A field oriented control of DTP-PMSM based on the vector space decomposition (VSD) was presented in [10]. The conventional VSD control for DTP induction motor was given in [11]. As specified by the VSD strategy, the machine model is transformed into three decoupled subspaces, identified as, $(\alpha, \beta)$ torque-component, $\left(\mathrm{z}_{1}, \mathrm{z}_{2}\right)$ harmonic-component and $\left(\mathrm{o}_{1}, \mathrm{o}_{2}\right)$ zero-sequence, respectively [12]-[18]. 
Direct torque control (DTC) is a technique used for high performance control of three phase electric drive systems [19]. It is characterized by simple structure which is independent of machine parameters and allowing a fast torque response. When applying the DTC for the DTP-PMSM, important harmonic stator currents are usually observed. These currents cause losses in the stator and thus deteriorate the machine's efficiency. According to the VSD technique, the basic DTC does not allow the control of the harmonics that appear in the subspace $\left(\mathrm{z}_{1}, \mathrm{z}_{2}\right)$.

With the view to minimize harmonics and hence improve the machine's efficiency, a modified Switching Table based DTC for five phase synchronous machine is proposed in reference [20]. In this approach the selection of the appropriate voltage is done in two steps. The same technique applied to DTPPMSM is presented in reference [21]. The disadvantage of this method is the necessity to locate the stator flux position not only in the $(\alpha, \beta)$ subspace but also in the $\left(\mathrm{z}_{1}, \mathrm{z}_{2}\right)$ subspace. Our contribution is to propose a modified switching table constituted by synthetic vectors allowing the torque control as well as the reduction of the currents in $\left(\mathrm{z}_{1}, \mathrm{z}_{2}\right)$ subspace.

\section{DTP-PMSM DYNAMIC MODEL}

Figure 1 and Figure 2 illustrate the DTP-PMSM and VSI-fed drive. The two three-phase windings are identical with two independent neutral points [12]. The DTP-PMSM is complex and high order system. The mathematical model of the motor is simplified by assuming that the motor windings are distributed sinusoidally, saturation and magnetic losses are neglected [22]. To obtain a practical model proper for control, the voltage space decomposition VSD is used [11]. The VSD is based on the transformation matrix expressed by (1).

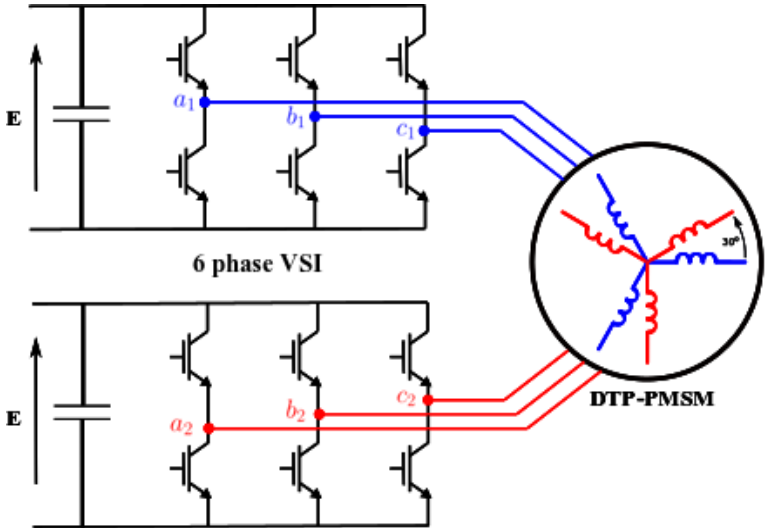

Figure 1. DTP-PMSM ship and six-phase voltage source inerter

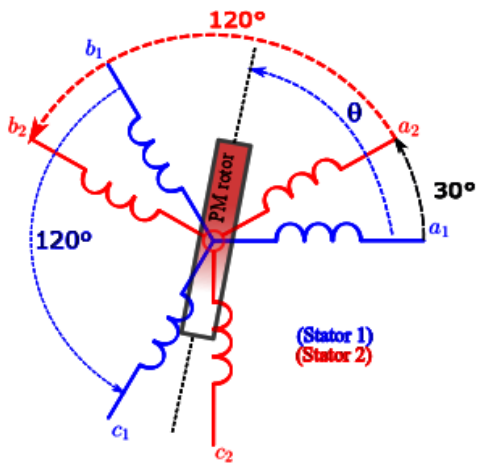

Figure 2. Windings of DTP-PMSM

$$
[T]=\frac{1}{\sqrt{3}}\left[\begin{array}{cccccc}
1 & -\frac{1}{2} & -\frac{1}{2} & -\frac{\sqrt{3}}{2} & \frac{\sqrt{3}}{2} & 0 \\
0 & \frac{\sqrt{3}}{2} & -\frac{\sqrt{3}}{2} & \frac{1}{2} & \frac{1}{2} & -1 \\
1 & -\frac{1}{2} & -\frac{1}{2} & -\frac{\sqrt{3}}{2} & \frac{\sqrt{3}}{2} & 0 \\
0 & -\frac{\sqrt{3}}{2} & \frac{\sqrt{3}}{2} & \frac{1}{2} & \frac{1}{2} & -1 \\
1 & 1 & 1 & 0 & 0 & 0 \\
0 & 0 & 0 & 1 & 1 & 1
\end{array}\right]
$$

Using this transformation, the system is projected into three orthogonal subspaces $(\alpha, \beta),\left(\mathrm{z}_{1}, \mathrm{z}_{2}\right)$ and $\left(\mathrm{o}_{1}, \mathrm{o}_{2}\right)$. The voltage equations, are expressed as [12]:

$$
\begin{aligned}
& {\left[\boldsymbol{V}_{\alpha \beta}\right]=\left[R_{s}\right]\left[\boldsymbol{i}_{\alpha \beta}\right]+\frac{d}{d t}\left[\boldsymbol{\psi}_{\alpha \beta}\right]=\left[R_{s}\right]\left[\boldsymbol{i}_{\alpha \beta}\right]+\frac{d}{d t}\left[\left[L_{\alpha \beta}\right]\left[\boldsymbol{i}_{\alpha \beta}\right]+\boldsymbol{\psi}_{P M} \cdot\left[\begin{array}{c}
\cos \boldsymbol{\theta} \\
\sin \boldsymbol{\theta}
\end{array}\right]\right.} \\
& {\left[\boldsymbol{V}_{z_{1,2}}\right]=\left[R_{s}\right]\left[\boldsymbol{i}_{z_{1,2}}\right]+\frac{d}{d t}\left[\boldsymbol{\psi}_{z_{1,2}}\right]=\left[R_{s}\right]\left[\boldsymbol{i}_{z_{1,2}}\right]+\left[L_{z}\right] \frac{d}{d t}\left[\boldsymbol{i}_{z_{1,2}}\right]}
\end{aligned}
$$




$$
\left[\boldsymbol{V}_{o_{1,2}}\right]=\left[R_{s}\right]\left[\boldsymbol{i}_{o_{1,2}}\right]+\frac{d}{d t}\left[\boldsymbol{\psi}_{o_{1,2}}\right]=\left[R_{s}\right]\left[\boldsymbol{i}_{o_{1,2}}\right]+\left[L_{o}\right] \frac{d}{d t}\left[\boldsymbol{i}_{o_{1,2}}\right]
$$

Where:

$$
\left[\boldsymbol{L}_{\boldsymbol{\alpha} \boldsymbol{\beta}}\right]=\left[\begin{array}{cc}
\frac{\left(L_{d}+L_{q}\right)}{2}+\frac{\left(L_{d}-L_{q}\right)}{2} \cos 2 \theta & \frac{\left(L_{d}-L_{q}\right)}{2} \sin 2 \theta \\
\frac{\left(L_{d}-L_{q}\right)}{2} \sin 2 \theta & \frac{\left(L_{d}+L_{q}\right)}{2}-\frac{\left(L_{d}-L_{q}\right)}{2} \cos 2 \theta
\end{array}\right]
$$

$L_{d}, L_{q}$ are $\mathrm{d}$ and $\mathrm{q}$ axis inductances.

$L_{z}$ and $L_{o}$ are the transformed stator self-leakage inductance.

$\psi_{P M}$ is the PM flux linkage.

$\theta$ is the rotor position.

Fundamental and harmonics are distributed as; i) the fundamental component is projected in $(\alpha, \beta)$, ii) harmonics with order $12 K^{\text {th }} \pm 1(K=1,2,3, \ldots)$ are projected in $(\alpha, \beta)$, iii) harmonics with order $6 K^{\text {th }} \pm$ $1(K=1,3,5, \ldots)$ are projected in $\left(\mathrm{z}_{1}, \mathrm{z}_{2}\right)$, and iv) the harmonics with order $3 K^{\text {th }}(K=1,3,5, \ldots)$ are projected in zero sequence subspace $\left(\mathrm{o}_{1}, \mathrm{O}_{2}\right)$.

Current components in the $(\alpha, \beta)$ subspace produce air gap flux and create the torque. Currents in $\left(\mathrm{z}_{1}, \mathrm{z}_{2}\right)$ and $\left(\mathrm{o}_{1}, \mathrm{O}_{2}\right)$ are all harmonics, they don't contribute to the electromechanical conversion and produce stator losses [23], [24]. To change to the $(d, q)$ rotating frame the following transformation matrix is applied:

$$
T_{r}=\left[\begin{array}{cc}
\cos \theta & \sin \theta \\
-\sin \theta & \cos \theta
\end{array}\right]
$$

Machine model in the $(d, q)$ plane:

$$
\begin{aligned}
& {\left[\begin{array}{l}
\boldsymbol{V}_{d} \\
\boldsymbol{V}_{q}
\end{array}\right]=\left[\begin{array}{cc}
R_{S} & 0 \\
0 & R_{s}
\end{array}\right]\left[\begin{array}{l}
\boldsymbol{i}_{d} \\
\boldsymbol{i}_{q}
\end{array}\right]+\frac{d}{d t}\left[\begin{array}{l}
\boldsymbol{\psi}_{d} \\
\boldsymbol{\psi}_{q}
\end{array}\right]+\frac{d \theta}{d t}\left[\begin{array}{c}
-\boldsymbol{\psi}_{q} \\
\boldsymbol{\psi}_{d}
\end{array}\right]} \\
& {\left[\begin{array}{l}
\boldsymbol{\psi}_{d} \\
\boldsymbol{\psi}_{q}
\end{array}\right]=\left[\begin{array}{cc}
L_{d} & 0 \\
0 & L_{q}
\end{array}\right]\left[\begin{array}{l}
\boldsymbol{i}_{d} \\
\boldsymbol{i}_{q}
\end{array}\right]+\sqrt{3}\left[\begin{array}{c}
\boldsymbol{\psi}_{P M} \\
0
\end{array}\right]}
\end{aligned}
$$

The electromagnetic torque is:

$$
\boldsymbol{T}_{e}=p\left(\boldsymbol{i}_{q} \boldsymbol{\psi}_{\mathrm{d}}-\boldsymbol{i}_{d} \boldsymbol{\psi}_{\mathrm{q}}\right)
$$

$p$ : pole pairs number.

\section{RESEARCH METHOD}

\subsection{Inverter voltage vectors}

The inverter shown in Figure 1 can provide 64 different voltage vectors. Each vector is presented by the subscript decimal number, corresponding to binary numbers $S_{\mathrm{a} 1} S_{\mathrm{b} 1} S_{\mathrm{c} 1} \mathrm{~S}_{\mathrm{a} 2} \mathrm{~S}_{\mathrm{b} 2} \mathrm{~S}_{\mathrm{c} 2}$. Where $\left(S=S_{\mathrm{a} 1}, S_{\mathrm{b} 1}, S_{\mathrm{c} 1}\right.$, $\mathrm{S}_{\mathrm{a} 2}, \mathrm{~S}_{\mathrm{b} 2}, \mathrm{~S}_{\mathrm{c} 2}$ ) are the device switch states. The phase voltages are expressed according to switch states by (9).

$$
\left[\begin{array}{l}
V_{a 1} \\
V_{b 1} \\
V_{c 1} \\
V_{a 2} \\
V_{b 2} \\
V_{c 2}
\end{array}\right]=\frac{\mathrm{E}}{3}\left[\begin{array}{cccccc}
2 & -1 & -1 & 0 & 0 & 0 \\
-1 & 2 & -1 & 0 & 0 & 0 \\
-1 & -1 & 2 & 0 & 0 & 0 \\
0 & 0 & 0 & 2 & -1 & -1 \\
0 & 0 & 0 & -1 & 2 & -1 \\
0 & 0 & 0 & -1 & -1 & 2
\end{array}\right]\left[\begin{array}{l}
S_{a 1} \\
S_{b 1} \\
S_{c 1} \\
S_{a 2} \\
S_{b 2} \\
S_{c 2}
\end{array}\right]
$$

While $\left(\mathrm{S}=\mathrm{S}_{\mathrm{a} 1}, \mathrm{~S}_{\mathrm{b} 1}, \mathrm{~S}_{\mathrm{c} 1}, \mathrm{~S}_{\mathrm{a} 2}, \mathrm{~S}_{\mathrm{b} 2}, \mathrm{~S}_{\mathrm{c} 2}\right.$ ) are the states of switches, $\mathrm{E}$ is the DC voltage. The 64 voltage vectors projected in each subspace are given by (10).

$$
\left[\begin{array}{llllll}
V_{\alpha} & V_{\beta} & V_{z 1} & V_{z 2} & V_{01} & V_{02}
\end{array}\right]^{T}=[T]\left[\begin{array}{llllll}
V_{a 1} & V_{b 1} & V_{c 1} & V_{a 2} & V_{b 2} & V_{c 2}
\end{array}\right]^{T}
$$

Thus, in $(\alpha, \beta)$ and $\left(\mathrm{z}_{1}, \mathrm{z}_{2}\right)$ subspaces, there are sixty non-zero voltage vectors and four zero voltage vectors $\left(V_{0}, V_{7}, V_{56}, V_{63}\right)[25]$ as shown in Figure 3 and Figure 4. 


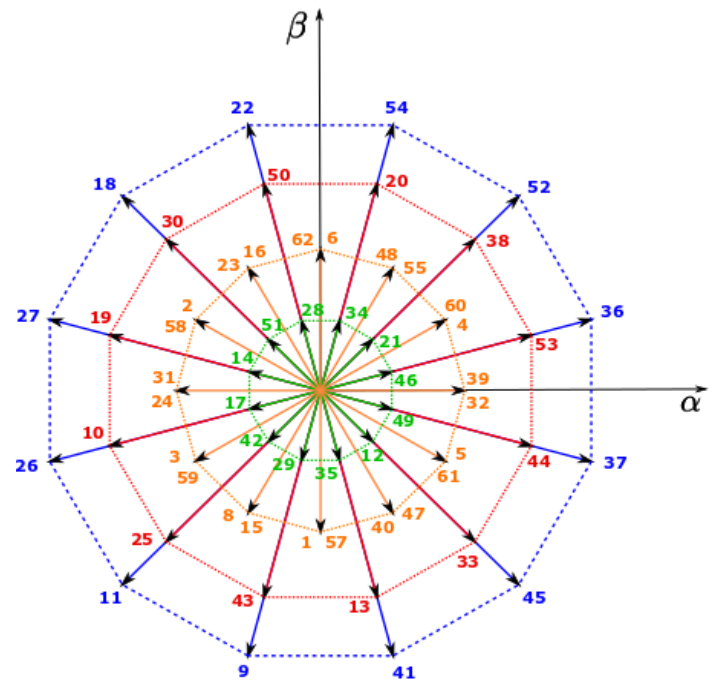

Figure 3. Voltage vectors diagram in $(\alpha, \beta)$

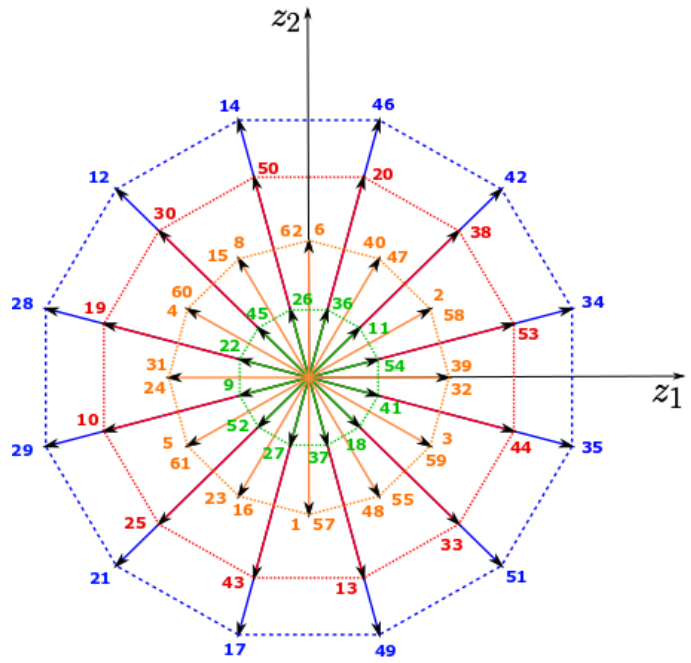

Figure 4. Voltage vectors diagram in $\left(\mathrm{z}_{1}, \mathrm{z}_{2}\right)$

According to the Figure 3, the voltage vectors are distributed in the $(\alpha, \beta)$ plane forming four dodecagons $\left(D_{1}, D_{2}, D_{3}, D_{4}\right)[26]$. Their amplitudes are given by (11).

$$
\left\{\begin{array}{c}
U_{D 1}=\frac{\sqrt{(2-\sqrt{3})}}{\sqrt{3}} E \\
U_{D 2}=\frac{1}{\sqrt{3}} E \\
U_{D 3}=\frac{\sqrt{2}}{\sqrt{3}} E \\
U_{D 4}=\frac{\sqrt{(2+\sqrt{3})}}{\sqrt{3}} E
\end{array}\right.
$$

We can notice from Figure 3 and Figure 4 that vectors of the outer dodecagon $\mathrm{D}_{4}$ in $(\alpha, \beta)$ subspace map in the inner dodecagon $\mathrm{D}_{1}$ of the $\left(\mathrm{z}_{1}, \mathrm{z}_{2}\right)$ subspace, the inner dodecagon $\mathrm{D}_{1}$ of $(\alpha, \beta)$ subspace forms the outer dodecagon $\mathrm{D}_{4}$ of $\left(\mathrm{z}_{1}, \mathrm{z}_{2}\right)$ subspace while the middle dodecagon space vector keeps the the same region.

\subsection{Conventional ST-DTC}

In the direct torque control scheme, torque and flux of DTP-PMSM are estimated. Two hysteresis comparators for torque and flux and a switching table are used to generate the inverter vectors as shown in Figure 5. The voltage vectors with the maximum amplitude divide the subspace $(\alpha, \beta)$ into 12 sectors as shown in Figure 6. This choice allows maximum use of the DC power supply and guarantees the application of low amplitude voltage vectors in the $\left(\mathrm{z}_{1}, \mathrm{z}_{2}\right)$ subspace. Each sector is delimited by two maximum vectors, as shown in Figure 6 . When the stator flux is in the sector $k$, the application of the vector $\mathrm{V}_{\mathrm{k}+2}$ leads to the increase of the flux and the torque whereas the application of $V_{k-4}$ causes their reduction. The application of the vector $\mathrm{V}_{\mathrm{k}+3}$ produces the reduction of the flux and the increase of the torque, the opposite effect is produced by the vector $\mathrm{V}_{\mathrm{k}-3}$. In summary, the choice of the voltage vector is carried out according to the Table 1. 


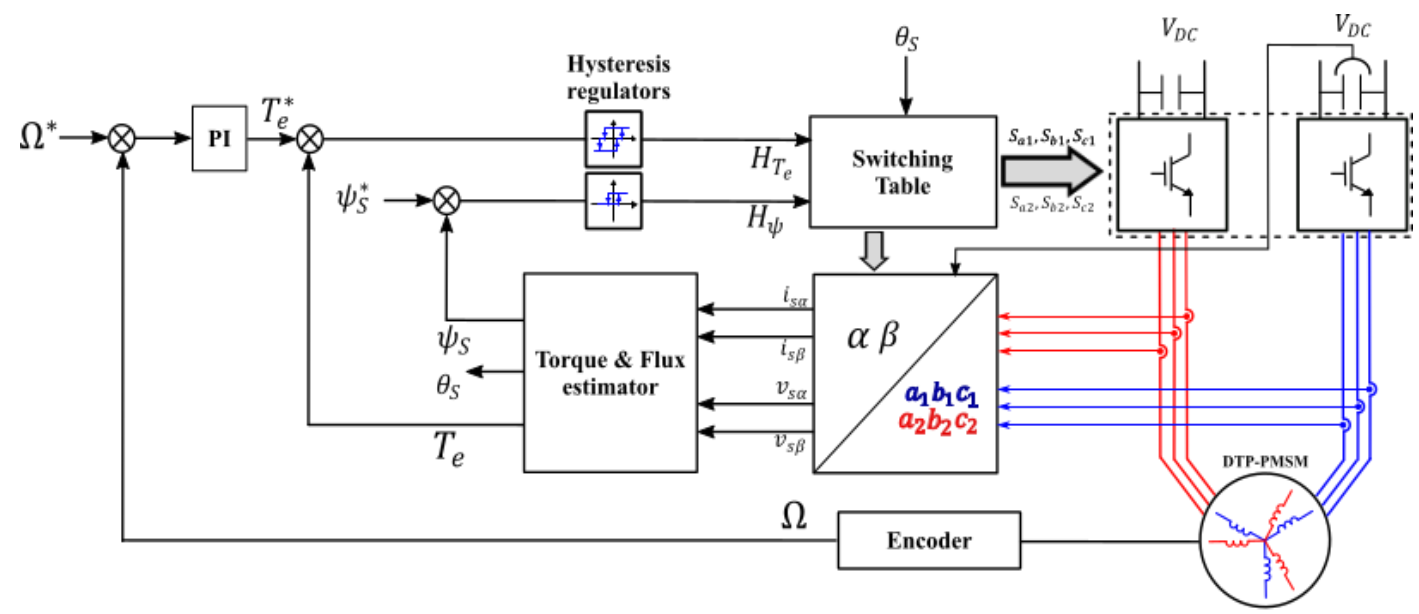

Figure 5. Conventional DTC diagram of DTP-PMSM drive

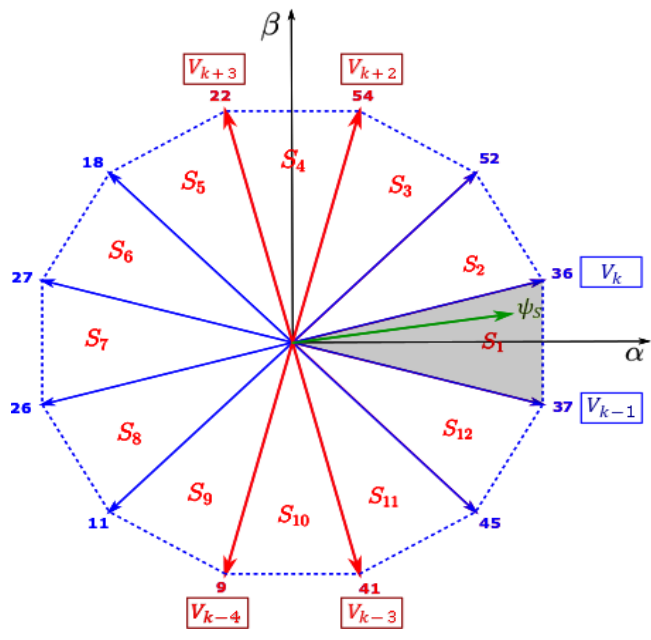

Figure 6. 12 sectors diagram and selection of voltage vectors

Table 1. Conventional DTC switching table

\begin{tabular}{ccccccc}
\hline & \multicolumn{6}{c}{ K Sector } \\
\hline $\mathrm{H}_{\Psi}$ & 1 & 1 & & & -1 \\
$\mathrm{H}_{\mathrm{T}_{\mathrm{e}}}$ & 1 & 0 & -1 & 1 & 0 & -1 \\
Applied & $V_{k+2}$ & $V_{\text {zero }}$ & $V_{k-3}$ & $V_{k+3}$ & $V_{\text {zero }}$ & $V_{k-4}$ \\
vector & & & & &
\end{tabular}

The generated torque and flux control signals $H_{\psi}$ and $H_{T_{e}}$ are defined as:

$$
\begin{aligned}
& \boldsymbol{H}_{T_{e}}=\left\{\begin{array}{c}
1 \text { if } T_{e}^{*}-T_{e} \geq \varepsilon_{T} \\
0 \text { if } T_{e}^{*}-T_{e}=0 \\
-1 \text { if } T_{e}^{*}-T_{e} \leq \varepsilon_{T}
\end{array}\right. \\
& \boldsymbol{H}_{\psi}=\left\{\begin{array}{c}
1 \text { if } \psi_{s}^{*}-\psi_{s} \geq \varepsilon_{\psi} \\
-1 \text { if } \psi_{s}^{*}-\psi_{s} \leq \varepsilon_{\psi}
\end{array}\right.
\end{aligned}
$$

\section{THE MODIFIED ST-DTC APPROACH}

The modified switching table DTC approach allows the decreasing of the current harmonics by reducing the currents in subspace $\left(\mathrm{z}_{1}, \mathrm{z}_{2}\right)$. As shown in Figure 7 the sixty non-zero voltage vectors of the 
subspace $(\alpha, \beta)$ can be divided into twelve groups of vectors $\left\{G_{1}, G_{2} \ldots, G_{12}\right\}$. Each group is composed of three vectors having the same direction, for the example $V_{36}, V_{53}$ and $V_{46}$ constitute the $\mathrm{G}_{1}$ group. Given this remark, the vectors of the same group will have the same effects on the flux and the torque.

The vectors belonging to the same group in $(\alpha, \beta)$ subspace change the direction and the module in $\left(\mathrm{z}_{1}, \mathrm{z}_{2}\right)$ subspace. Indeed, for a given group the largest vector of the Dodecagon $\mathrm{D}_{4}$ changes direction in subspace $\left(\mathrm{z}_{1}, \mathrm{z}_{2}\right)$ and its module becomes the smallest. The second vector of the group belonging to the Dodecagon $\mathrm{D}_{3}$ keeps the same module but changes direction and becomes opposite to the preceding vector. As illustrated in Figure 8, the vectors $V_{53}, V_{46}$ and $V_{36}$ of $\mathrm{D}_{3}, \mathrm{D}_{1}$ and $\mathrm{D}_{4}$ respectively and which constitute the group $\mathrm{G}_{1}$ have the same direction. However, in the $\left(\mathrm{z}_{1}, \mathrm{z}_{2}\right), V_{53}$ has an opposite direction to $V_{36}$ and $V_{46}$ as shown in Figure 8.

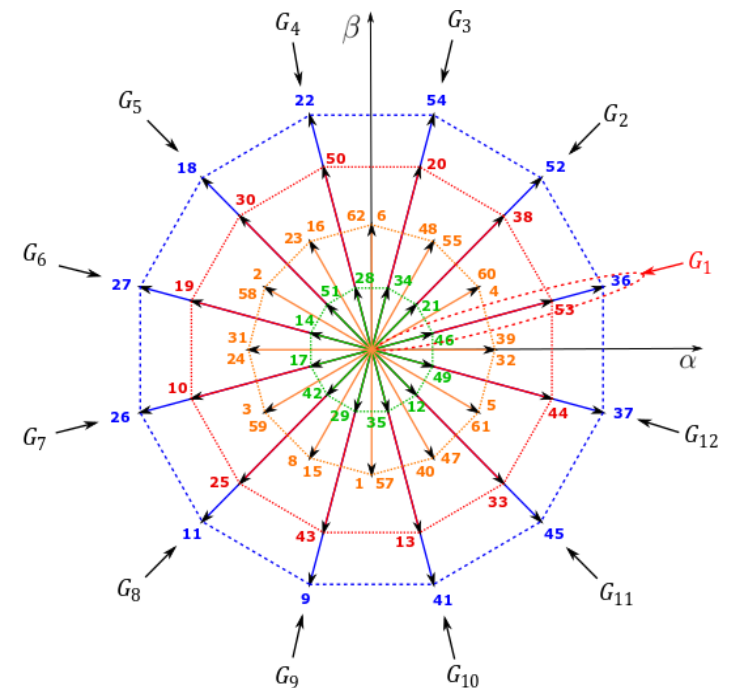

Figure 7. Groups of vectors $\left\{G_{1}, G_{2} \ldots, G_{12}\right\}$ in $(\alpha, \beta)$

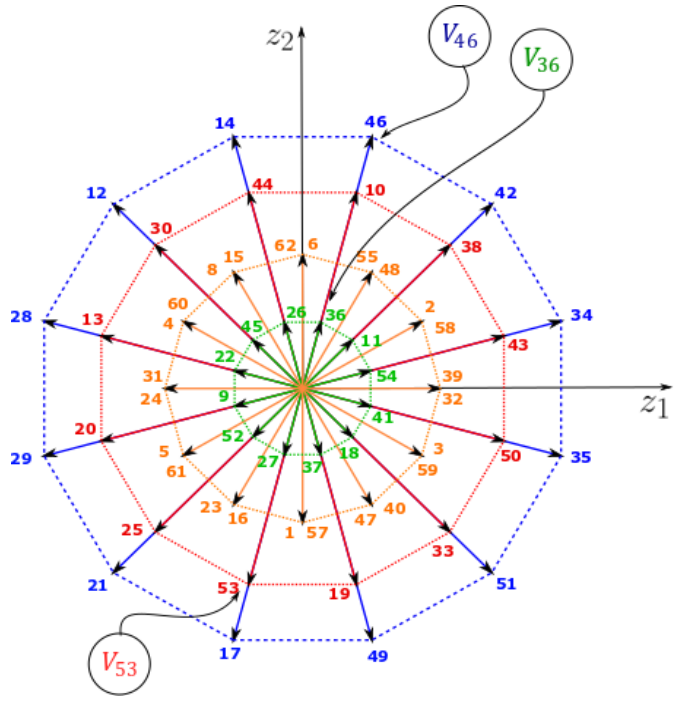

Figure 8. Vectors $V_{36}, V_{46}$ and $V_{53}$ in $\left(\mathrm{z}_{1}, \mathrm{z}_{2}\right)$

Consequently, the use of vector of $\mathrm{D}_{3}$ and vector of $\mathrm{D}_{4}$ together allows controlling current in $\left(\mathrm{z}_{1}, \mathrm{z}_{2}\right)$ and then reducing current harmonics. For the example if $V_{36}$ is chosen according to the switching table, the vector $V_{52}$ must be applied with $V_{36}$ to cancel its effect in $\left(\mathrm{z}_{1}, \mathrm{z}_{2}\right)$ subspace. The (12) relation gives the time allotted for each vector:

$$
\left\{\begin{array}{c}
T_{1}\left(V_{36}\right)_{z_{1} z_{2}}+T_{2}\left(V_{53}\right)_{z_{1} z_{2}}=\overrightarrow{0} \\
T_{1}+T_{2}=T_{s}
\end{array}\right.
$$

Where $T_{S}$ is the sampling time. The calculation of the times gives:

$$
\left\{\begin{array}{l}
T_{1}=(\sqrt{3}-1) \cdot T_{S} \\
T_{2}=(2-\sqrt{3}) \cdot T_{s}
\end{array}\right.
$$

Thus, the proposed approach consists of replacing the 12 vectors of $\mathrm{D}_{4}$ used in the conventional DTC by a combination of vectors of $\mathrm{D}_{3}$ and $\mathrm{D}_{4}$ as depicted in Table 2 . The module of synthetic vector is given by (14).

$$
\left\|V_{s}\right\|=\left\|\frac{T_{1} V_{36}+T_{2} V_{53}}{T s}\right\|=(\sqrt{6}-\sqrt{2}) E
$$

The synthetic vector has a module slightly lower than that generated by the classical DTC.

$$
\eta=\frac{\left\|V_{S}\right\|}{\left\|V_{36}\right\|} \times 100 \%=92,82 \%
$$


Table 2. Synthetic vectors used in modified ST-DTC

\begin{tabular}{cc}
\hline Classical DTC & Modified DTC \\
\hline$V_{36}$ & $T_{1} V_{36}+T_{2} V_{53}$ \\
$V_{52}$ & $T_{1} V_{52}+T_{2} V_{38}$ \\
$V_{54}$ & $T_{1} V_{54}+T_{2} V_{20}$ \\
$V_{22}$ & $T_{1} V_{22}+T_{2} V_{50}$ \\
$V_{18}$ & $T_{1} V_{18}+T_{2} V_{30}$ \\
$V_{26}$ & $T_{1} V_{26}+T_{2} V_{19}$ \\
$V_{27}$ & $T_{1} V_{27}+T_{2} V_{10}$ \\
$V_{11}$ & $T_{1} V_{11}+T_{2} V_{25}$ \\
$V_{9}$ & $T_{1} V_{9}+T_{2} V_{43}$ \\
$V_{41}$ & $T_{1} V_{41}+T_{2} V_{13}$ \\
$V_{45}$ & $T_{1} V_{45}+T_{2} V_{33}$ \\
$V_{37}$ & $T_{1} V_{37}+T_{2} V_{44}$ \\
\hline
\end{tabular}

\section{RESULTS AND DISCUSSION}

The simulations via MATLAB/Simulink environment were performed using information found in Table 3 [21]. The two studied strategies conventional and proposed ST-DTC for DTP-PMSM drives, have been tested and results are presented in Figures 9 to 15. As shown in Figure 9, using the classic DTC strategy results in a non-sinusoidal phase current, indeed, the current contains a large quantity of the $5^{\text {th }}$ and $7^{\text {th }}$ harmonics which are dominant $(\mathrm{THD}=51.6 \%)$ as shown in Figure 11. These current components do not contribute to the electromechanical conversion and only generate losses.

Figure 10 shows the phase current corresponding to the proposed ST-DTC strategy. It can be observed that the shape of the current is nearly sinusoidal, harmonic analysis presented in Figure 12 shows that the harmonics are significantly reduced (THD about $11 \%$ ), this is due to the fact that modified DTC method allows the control of current components in the $\left(\mathrm{z}_{1}, \mathrm{z}_{2}\right)$ subspace, and this consequently allows the reduction of harmonic currents. The Figure 13 and Figure 14 represents the currents in $(\alpha, \beta)$ subspace, we notice that for the two approaches we have the same amplitude, low ripple and regular trajectory. In Figure 15 (a) and Figure 15 (b) the torque presents the same appearance for both strategies. The torque quality is not affected by the presence of aforementioned harmonics. We also notice that the velocity reaches its setpoint with good dynamic and zero static error.

Table 3. Simulation parameters

\begin{tabular}{ll}
\hline \multicolumn{1}{c}{ Designation } & \multicolumn{1}{c}{ Value } \\
\hline DC voltage $E$ & $50 \mathrm{~V}$ \\
Resistance $R_{s}$ & $1.09 \Omega$ \\
D axis inductance $L_{d}$ & $2.142 \mathrm{mH}$ \\
Q axis inductance $L_{q}$ & $2.142 \mathrm{mH}$ \\
Permanent magnet flux $\psi_{\mathrm{PM}}$ & $0.0734 \mathrm{~Wb}$ \\
Inertia moment $J$ & $89.10^{-3} \mathrm{kgm}^{2}$ \\
Viscous friction coefficient $f$ & $0.01 \mathrm{Nms} / \mathrm{rad}$ \\
Pole pairs number $p$ & 5 \\
\hline
\end{tabular}

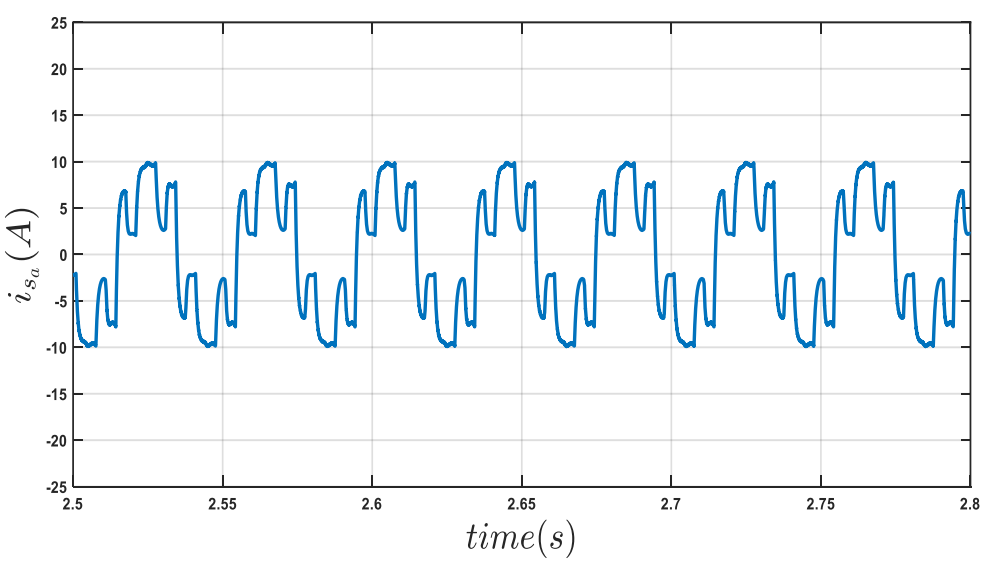

Figure 9. Stator phase current conventional DTC 


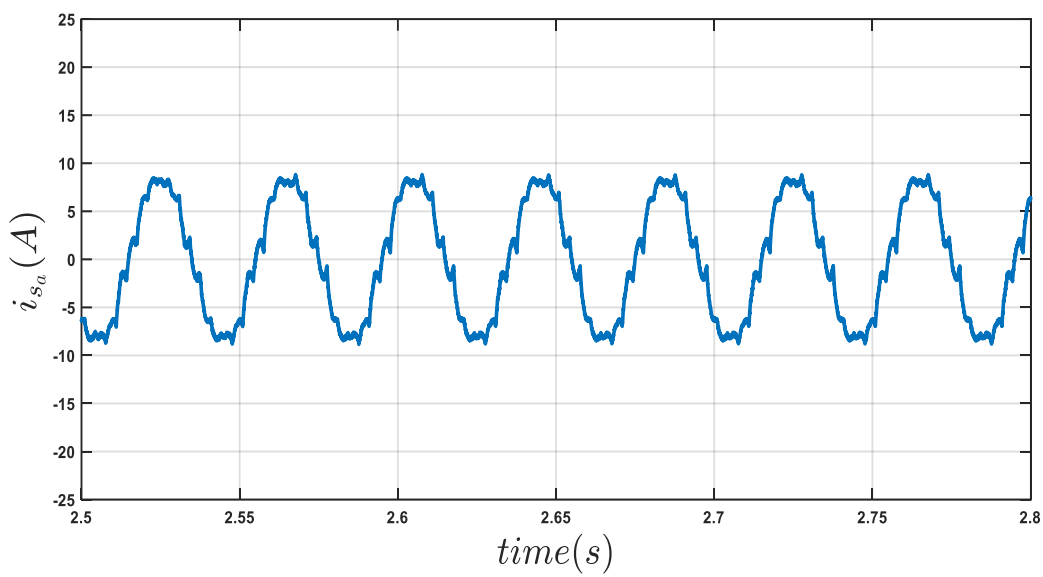

Figure 10. Stator phase current modified DTC

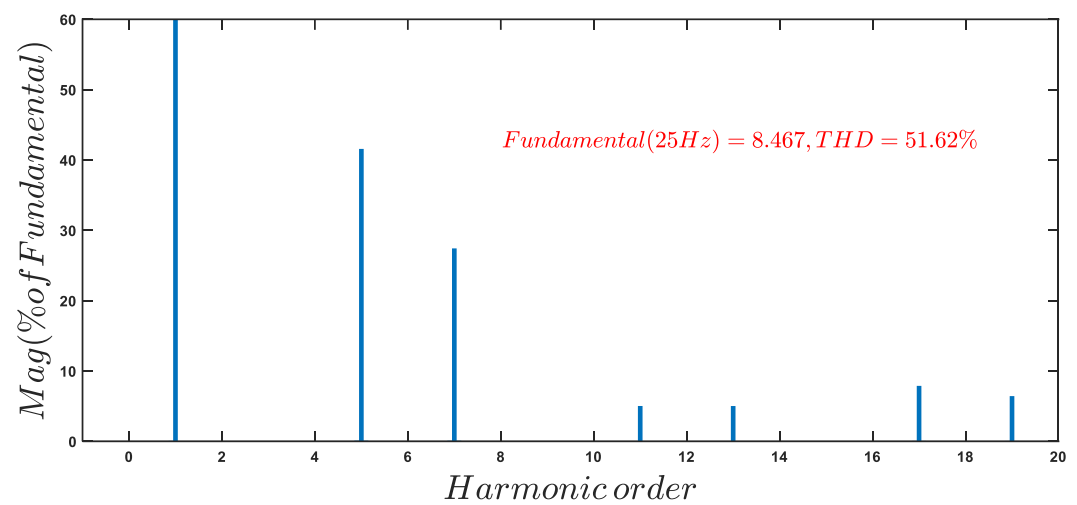

Figure 11. Stator phase current harmonic analysis conventional DTC

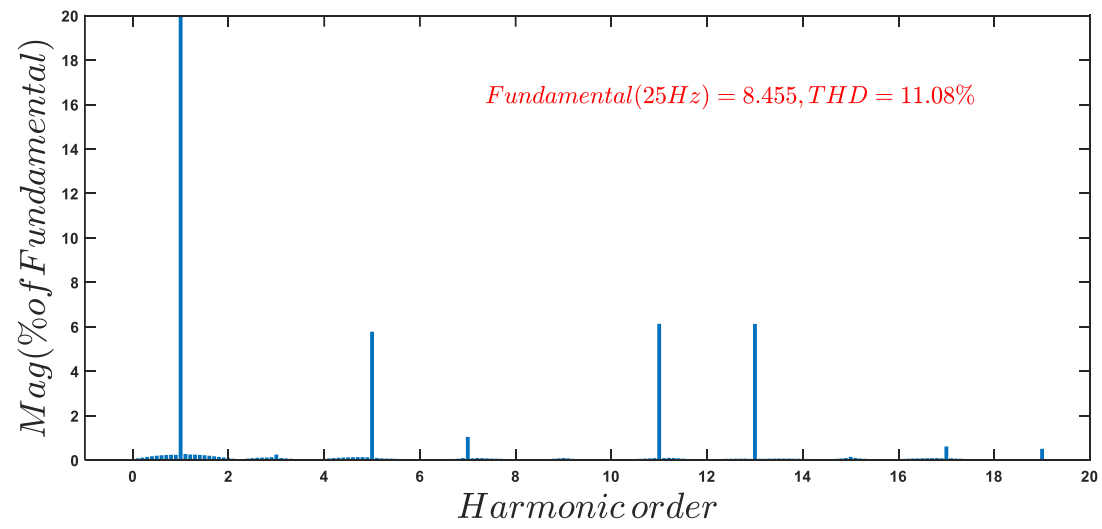

Figure 12. Stator phase current harmonic analysis modified DTC 


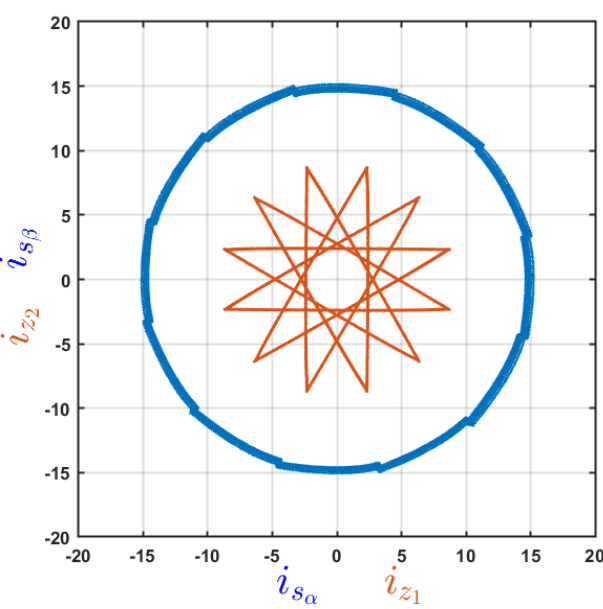

Figure 13. Currents in $(\alpha, \beta)$ and $\left(\mathrm{z}_{1}, \mathrm{z}_{2}\right)$ subspaces conventional DTC

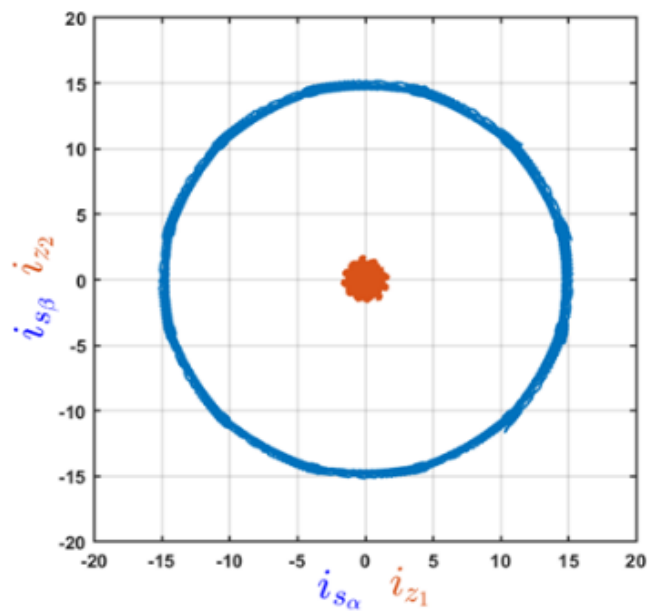

Figure 14. Currents in $(\alpha, \beta)$ and $\left(\mathrm{z}_{1}, \mathrm{z}_{2}\right)$ subspaces modified DTC
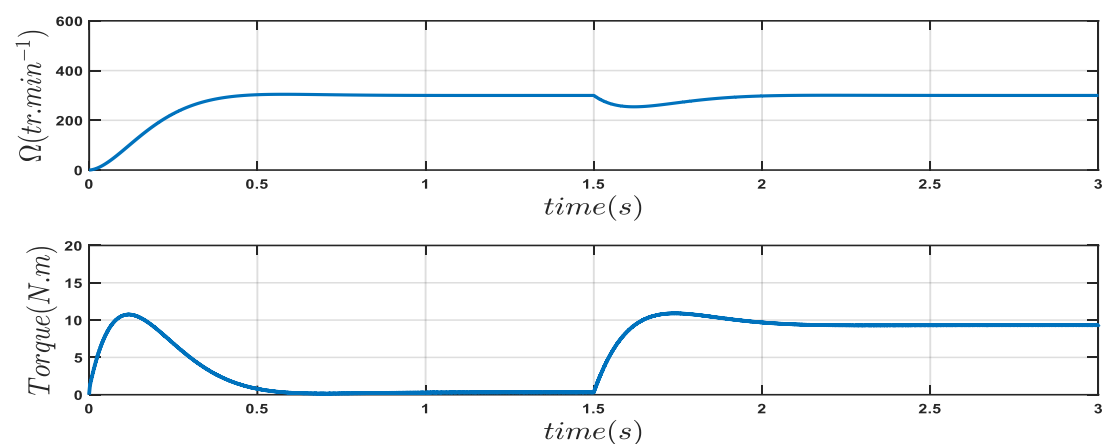

(a)
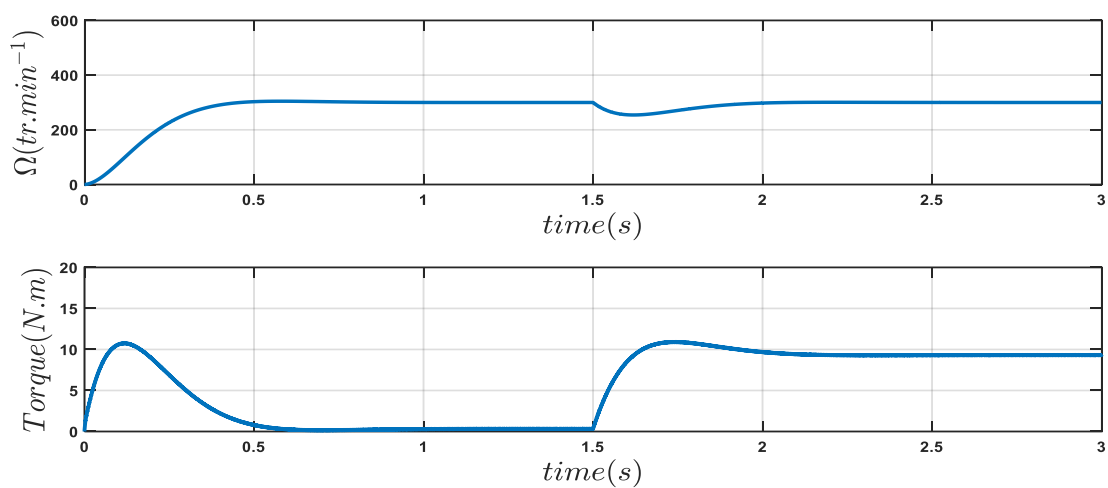

(b)

Figure 15. Speed and torque dynamic for (a) conventional DTC; (b) modified DTC

\section{CONCLUSION}

DTC is one of the strategies used for high performance electrical drive systems. Applied to DTPPMSM the conventional DTC leads to significant harmonic currents. To deal with this problem, a DTC with a modified switching table has been proposed to control the DTP-PMSM. The purpose of this method is to minimize the harmonics of the stator current. It is based on the use of 12 voltage vectors synthesized in a two-step process. This technique allows the elaborating of the most suitable inverter voltage vector which permits not only the control of variables in $(\alpha, \beta)$ subspace but also the reduction of currents in the $\left(\mathrm{z}_{1}, \mathrm{z}_{2}\right)$ subspace. Simulations have shown the effectiveness of the modified strategy to minimize harmonic current and increase system efficiency, while preserving the benefits and the merits of the classical technique. 


\section{REFERENCES}

[1] M. Hasoun, A. El Afia, K. Chikh, M. Khafallah, and K. Benkirane, "A PWM strategy for dual three-phase PMSM using 12-sector vector space decomposition for electric ship propulsion," in 2018 19th IEEE Mediterranean Electrotechnical Conference (MELECON), 2018, pp. 243-248, doi: 10.1109/MELCON.2018.8379101.

[2] Y. Guo, and X. Yan, "Research on matrix converter control multi-phase PMSM for all electric ship,"in 2011 International Conference on Electrical and Control Engineering, 2011, pp. 3120-3123, doi: 10.1109/ICECENG.2011.6057186.

[3] H. Echeikh, R. Trabelsi, H. Kesraoui, A. Iqbal, and M. F. Mimouni, "Torque ripples improvement of direct torque controlled five-phase induction motor drive using backstepping control," International Journal of Power Electronics and Drive Systems (IJPEDS), vol. 11, no. 1, pp. 64-74, 2020, doi: 10.11591/ijpeds.v11.i1.pp64-74.

[4] A. Taibi, K. Hartani, A. Allali, "New DTC strategy of multi-machines single-inverter systems for electric vehicle traction applications," International Journal of Power Electronics and Drive Systems (IJPEDS), vol. 11, no. 2, pp. 641-650, 2020, doi: 10.11591/ijpeds.v11.i2.pp641-650.

[5] E. Levi, "Multiphase electric machines for variable-speed applications," IEEE Transactions on Industrial Electronics, vol. 55, no. 5, pp. 1893-1909, May 2008, doi: 10.1109/TIE.2008.918488.

[6] M. M. El Kholy, and Z. M. S. El Barbary, "Performance analysis of indirect rotor field orientation five phase induction motor using eight switch inverter," International Journal of Power Electronics and Drive Systems, vol. 8, no. 3, pp. 1128-1134, 2017, doi: 10.11591/ijpeds.v8.i3.pp1128-1138.

[7] M. B. R. Correa, C. B. Jacobina, C. R. da Silva, A. M. N. Lima, and E. R. C. da Silva, "Six-phase AC drive system with reduced common-mode voltage," in IEEE International Electric Machines and Drives Conference, IEMDC'03, 2003, vol. 3, pp. 1852-1858, doi: 10.1109/IEMDC.2003.1210705.

[8] A. K. Mohanty, and K. B. Yadav, "Estimation of excitation capacitance requirement of an isolated multi-phase induction generator for power generation," International Journal of Power Electronics and Drive Systems (IJPEDS), vol. 7, no. 2, pp. 561-567, 2016, doi: 10.11591/ijpeds.v7.i2.pp561-567.

[9] D. Dujic, A. Iqbal, and E. Levi, "A space vector PWM technique for symetrical six-phase voltage source inverters," EPE Journal, vol. 7, no. 1, pp. 24-32, 2015, doi: 10.1080/09398368.2007.11463639.

[10] Y. Yu, L. Gao, Y. Liu, and F. Chai, "24-Sector space vector decomposition for a dual three-phase PMSM," in 2014 17th International Conference on Electrical Machines and Systems, 2014, pp. 1601-1606, doi: 10.1109/ICEMS.2014.7013733.

[11] Y. Zhao, and T. A. Lipo, "Space vector PWM control of dual three-phase induction machine using vector space decomposition," IEEE Transactions on Industry Applications, 1995, vol. 31, no. 5, pp. 1100-1109, doi: $10.1109 / 28.464525$.

[12] M. Hasoun, A. El Afia, M. Khafallah, and K. Benkirane, "Experimental implementation a PWM strategy for dual three-phase PMSM using 12-sector vector space decomposition applied on electric ship propulsion," International Journal of Power Electronics and Drive System (IJPEDS), vol. 11, no. 4, pp. 1701-1710, 2020, doi: 10.11591/ijpeds.v11.i4.pp1701-1710.

[13] Z. Wang, J. Chen, M. Cheng, and Na Ren, "Vector space decomposition based control of neutral-point-clamping (NPC) three-level inverters fed dual three-phase PMSM drives," in IECON 2016 - 42nd Annual Conference of the IEEE Industrial Electronics Society, 2016, pp. 2988-2993, doi: 10.1109/IECON.2016.7793845.

[14] Z. Wang, Y. Wang, J. Chen, and Y. Hu, "Decoupled vector space decomposition based space vector modulation for dual three-phase three-level motor drives," IEEE Transactions on Power Electronics, vol. 33, no. 12, pp. 10683-10697, 2018, doi: 10.1109/TPEL.2018.2811391.

[15] L. Yuan, M.-L. Chen, J.-Q. Shen, and F. Xiao, "Current harmonics elimination control method for six-phase PM synchronous motor drives," ISA Transactions, vol. 59, pp. 443-449, 2015, doi: 10.1016/j.isatra.2015.09.013.

[16] V. Oleschuk, V. Ermuratskii, and F. Barrero, "Combined PWM control of multi-inverter installation with two DC-links," in 2015 International Conference on Electrical Drives and Power Electronics (EDPE), 2015, pp. 9498, doi: 10.1109/EDPE.2015.7325276.

[17] H. Zhang, S. Luo, Y. Yu, and L. Liu, "Study on series control method for dual three-phase PMSM based on space vector pulse width modulation," International Journal of Control and Automation, vol. 8, no. 1, pp. 197-210, 2015, doi: 10.14257/ijca.2015.8.1.18.

[18] K. Marouani, L. Baghli, D. Hadiouche, A. Kheloui, and A. Rezzoug, "A new PWM strategy based on a 24-sector vector space decomposition for a six-phase VSI-fed dual stator induction motor," IEEE Transactions on Industrial Electronics, vol. 55, no. 5, pp. 1910-1920, May 2008, doi: 10.1109/TIE.2008.918486.

[19] Z. Q. Zhu, Yuan Ren, and Jiaming Liu, "Improved torque regulator to reduce steady-state error of torque response for diret torque control of PMSM Drives," IET Electric Power Applications, vol. 8, no. 3, pp. 108-116, 2014, doi: 10.1049/iet-epa.2013.0180.

[20] Y. Gao, and L. Parsa, "Modified direct torque control of five-phase permanent magnet synchronous motor drives," in APEC 07 - Twenty-Second Annual IEEE Applied Power Electronics Conference and Exposition, 2007, pp. 1428-1433, doi: 10.1109/APEX.2007.357704.

[21] K. D. Hoang, Y. Ren, Z. Q. Zhu, and M. Foster, "Modified switching-table strategy for reduction of current harmonics in direct torque controlled for dual three-phase permanent magnet synchronous machine drives," IET Electric Power Applications, vol. 9, no. 1, pp. 1-19, 2015, doi: 10.1049/iet-epa.2013.0388. 
[22] P. Zhang, W. Zhang, and X. Shen, "Comparative study of field-oriented control in different coordinate systems for DTP-PMSM," in 2013 International Conference on Electrical Machines and Systems (ICEMS), 2013, pp. 1015-1019, doi: 10.1109/ICEMS.2013.6713359.

[23] M. Hasoun, A. E. Afia, and M. Khafallah, "Performance comparison of two-SVPWM-strategies based vector space decomposition controlled dual three-phase PMSM for electric ship propulsion," in 2019 7th International Renewable and Sustainable Energy Conference IRSEC, 2019, pp. 1-8, doi: 10.1109/IRSEC48032.2019.9078209.

[24] M. Hasoun, A. El afia, and M. Khafallah, "Field oriented control of dual three-phase PMSM based vector space decomposition for electric ship propulsion," in 2019 International Conference of Computer Science and Renewable Energies ICCSRE, 2019, pp. 1-6, doi: 10.1109/ICCSRE.2019.8807703.

[25] M. Hasoun, A. El Afia, M. Khafallah, K. and Benkirane, "Field oriented control based on a 24-sector vector space decomposition for dual three-phase PMSM applied on electric ship propulsion," International Journal of Power Electronics and Drive System (IJPEDS), vol. 11, no. 3, pp. 1175-1187, 2020, doi: 10.11591/ijpeds.v11.i3.pp1175-1187.

[26] J. Karttunen, S. Kallio, P. Peltoniemi, P. Silventoinen, and O. Pyrhönen, "Dual three-phase permanent magnet synchronous machine supplied by two independent voltage source inverters," in International Symposium on Power Electronics Power Electronics, Electrical Drives, Automation and Motion, pp. 741-747, 2012, doi: 10.1109/SPEEDAM.2012.6264448.

\section{BIOGRAPHIES OF AUTHORS}

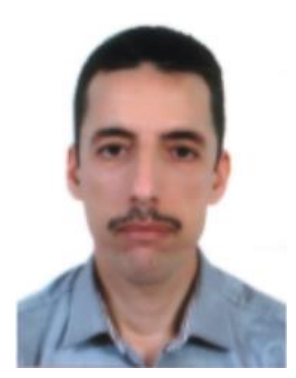

Aziz El Afia received B.Sc., M. Sc. degrees from Hassan II University, Casablanca in 1990, 1994 respectively and the Ph.D. degree in Electrical Engineering from The National High School of Electrical and Mechanical Engineering (ENSEM), Hassan II University, Casablanca in 2009. Since 2011 he has been working as a Professor of Power Electronic at the National High School of Arts and Crafts of Casablanca (ENSAM). His current research interests are in power electronics converters and control of machines and drives for application from automotive to renewable energy. Email: aziz.elafia@univh2c.ma

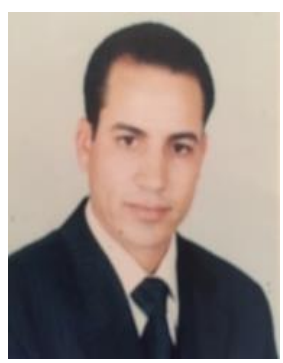

Mhammed Hasoun was born in Khouribga Morocco in 1969. He received the Engineering degree in 1995 from Navy Royal School, Military Navy, Casablanca, Morocco; and the certificate of Navy Safety in 1996 at Cherbourg, France. From 1996 to 2008, he occupied the function of propulsion engineering chief in military ships various. In 2008 he joined the Navy Royal School, where he is currently professor at the Engineering Department. His current research interests are in the application of power electronics converters and motor drives for electric propulsion systems. Email: mhammedhasoun@gmail.com

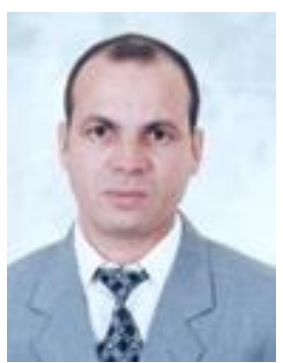

Mohamed Khafallah was born in Morocco in 1964. He received B.Sc., M.Sc. and Doctorate degrees from Hassan II University, Casablanca, in 1989, 1991 and 1995 respectively, all in Electrical Engineering. In 1995 he joined the National High School of Electricity and Mechanics (ENSEM), Hassan II University, Casablanca, Morocco, where he is currently professor tutor in the Department Electrical Engineering and chief of Laboratory Energy and Electrical Systems (LESE). His main research interests the application of power electronics converts and motor drives. He has published a lot of research papers in international journals, conference proceedings as well as chapters of books. Email: m.khafallah@gmail.com

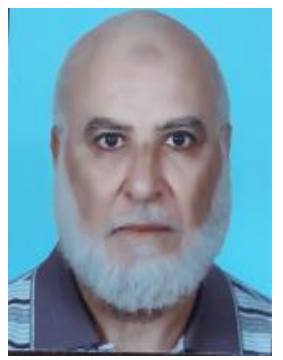

Karim Benkirane was born in Morocco in 1960. He received B.Sc., M.Sc. and Doctorate degrees from Mohamed V University Rabat and University of Sciences and Technics at Languedoc (USTL), France, in 1978, 1983 and 1986 respectively, all in Electronics Engineering. In 1987 he joined the Royal Navy School (ERN), Casablanca, Morocco, where he is currently professor tutor in the Department Research. His main research interests the application of power electronics converts and motor drives. He has published a lot of research papers in international journals. Email:karbenkirane@yahoo.fr 